\title{
Feminismo, filosofia e teoria social: mulheres em debate
}

\author{
Feminism, Philosophy and Social Theory: Women in Debate
}

Patrícia da Silva Santos ${ }^{1}$ (D) 0000-0002-1266-1311

'Universidade Federal do Pará, Faculdade de Ciências Sociais, Belém, PA, Brasil. 66075-110-fcs@ufpa.br

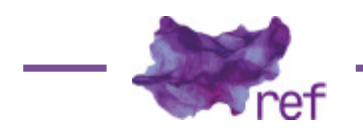

BENHABIB, Seyla; BUTLER, Judith; CORNELL, Drucilla; FRASER, Nancy. Debates feministas. Um intercâmbio filosófico.

Trad. de Fernanda Veríssimo. São Paulo: Editora Unesp, 2018.

\begin{abstract}
O discurso filosófico e teórico nas sociedades ocidentais estabeleceu-se, por muito tempo, como território predominantemente masculino. O debate acerca da boa vida e as concepções em torno de suas instituições subjacentes à filosofia e à teoria social eram, até há pouco, protagonizados por homens que se apresentavam como as vozes "neutras" e "objetivas" de nossas formulações teóricas. O que acontece quando quatro feministas se reúnem para debater suas questões em profundo diálogo com algumas das mais relevantes tendências teóricas contemporâneas - como a teoria crítica, o pós-estruturalismo e a psicanálise? É claro que não se poderia exigir dessa empreitada a homogeneidade e o consenso próprios da suposta "universalidade" com que se disfarçou a moderna racionalidade ocidental.

Debates feministas, publicado originalmente no início dos anos 1990 e só agora disponível em edição brasileira, não é somente um livro sobre teoria feminista (uma das lições implícitas é justamente a impossibilidade de se pensar tal concepção no singular). É um testemunho de que o abalo geral provocado pelo pensamento contemporâneo em concepções basilares como identidade, normas e cultura exige que sejam autorizados sujeitos de discurso até então silenciados para que a filosofia e a teoria social se dispam da falsa neutralidade e incorporem os ruídos do nãoidêntico, da subversão e da diferença. Em seus debates, Seyla Benhabib, Judith Butler, Drucilla Cornell e Nancy Fraser buscam apontar o lugar dos discursos feministas nessa tarefa de reelaboração do pensamento filosófico e teórico - as quatro pensadoras já apareciam, juntamente a outras, em volume publicado no Brasil há um bom tempo (Seyla BENHABIB; Drucilla CORNELL, 1987).

Debates feministas, que conta com uma introdução de Linda Nicholson, está dividido em duas partes, intituladas "Ensaios" e "Réplicas", respectivamente. Essa divisão espelha o caráter combativo dos argumentos das quatro grandes teóricas estadunidenses. Cada um dos ensaios iniciais é pensado de modo a espelhar embates entre feminismo e teoria social "pós-moderna" (termo, aliás, também em debate, visto que não é aceito igualmente por todas as pensadoras). Nesse sentido, vertentes originais e hodiernas da teoria crítica, assim como teses pós-estruturalistas - principalmente as concebidas por Foucault e Derrida - e a psicanálise lacaniana são escrutinados via leituras feministas. Aqueles postulados todos - elaborados por homens, vale lembrar - levantaram, cada um a seu modo, questionamentos importantes em torno das concepções de sujeito, história, cultura, dominação etc. O feminismo contemporâneo vale-se, em
\end{abstract}


grande medida, de tais questionamentos para contar uma outra história, com outras formas de subjetividade e de resistência, mas não o faz de maneira consensual, conforme mencionado. 0 volume Debates feministas, mesmo limitado a um grupo muito restrito de feministas, espelha bem essa pluralidade.

Nesse sentido, a contribuição de Seyla Benhabib para a primeira parte do volume é enfática ao questionar a aliança entre feminismo e pós-modernidade. Para ela, a adoção feminista inquestionável de teses como a morte do sujeito, a morte da história e a morte da metafísica deixaria poucas chances para reflexões sobre autonomia, acerca de possibilidades de emancipação feminina e a respeito de critérios normativos mínimos para o combate à desigualdade de gênero. A aliança com o pós-modernismo implicaria "desistir da esperança utópica no outro integral." (Seyla BENHABIB, 2018, p. 59)

Bem distinta é a perspectiva de Judith Butler para quem o termo pós-modernidade seria uma estratégia para desqualificar uma ampla gama de reflexões diversas e pouco contribuiria para os debates contemporâneos (Judith BUTLER, 2018). Assumindo posições foucaultianas, a pensadora defende a não necessidade de o feminismo partir de um sujeito universal. $O$ feminismo cumpriria melhor sua função caso assumisse em definitivo a tarefa de implodir a concepção de identidades fixas de gênero, apontando as genealogias discursivas que as constituíram. A consciência do caráter performático das subjetividades de gênero inscreveria a possibilidade de ressignificação dos sujeitos e, nesse sentido, cumpriria uma função política. Vale mencionar que Problemas de gênero, com sua exigência enfática de que o sujeito do feminismo não se restrinja às mulheres, havia sido publicado pouco antes da realização desses debates (Judith BUTLER, 2003).

Em sua primeira contribuição, Nancy Fraser, por sua vez, tenta estabelecer um diálogo entre as concepções teórico-críticas que baseiam as reflexões de Benhabib e a perspectiva pósestruturalista defendida por Butler. Para ela, haveria uma falsa antítese nesse debate e o feminismo não precisaria necessariamente escolher entre uma vertente e outra. Sua conclusão é de que as "feministas precisam de construção e desconstrução, desestabilização do significado e projeção de esperança utópica" (Nancy FRASER, 2018, p. 114). A ressignificação defendida por Butler não seria capaz, por si só, de desenvolver as "capacidades críticas" das mulheres em função de uma atuação política emancipatória, assim como a rejeição radical do pós-estruturalismo por parte de Benhabib desautorizaria a possibilidade de reconhecimento dos discursos de poder que estabelecem culturalmente as diferenças de gênero. Por isso, defende a necessidade de reunir os pontos positivos de cada uma das perspectivas.

Já Drucilla Cornell parte de um referencial teórico distinto, constituído pela psicanálise lacaniana. Para ela, as teses de Lacan, embora não tenham sido construídas em função de interesses feministas (muito pelo contrário, aliás), podem ser empregadas no sentido de contribuir para pensar a subjetividade das mulheres de maneira liberada do modelo hegemônico de sujeito - que se baseia na masculinidade. O sujeito feminino, justamente por ser caracterizado pela "falta", encerraria possibilidades plurais: "se mulher é falta [...], ela pode 'ser' qualquer coisa" (Drucilla CORNELL, 2018, p. 143). Essa reflexão sobre as possibilidades de subjetividade não falocêntrica também se relaciona à possibilidade de construção de um feminismo ético, baseado na relação não violenta com o outro. Cornell dialoga, além disso, com outros pensadores muito discutidos nos anos 1990, como Jacques Derrida, Ludwig Wittgenstein e John Rawls.

A segunda parte do livro, escrita por volta de três anos depois dos textos originais (que se limitavam às contribuições de Benhabib, Butler e Fraser; tendo o primeiro texto de Cornell sido também incluído nesse segundo momento), denuncia alguns problemas inerentes à empreitada proposta pelas autoras. Nessa parte do livro, as divergências entre as pensadoras são elaboradas de modo mais direto e as rusgas são expressas em formulações mais combativas. Cada uma delas responde às críticas e debate as contribuições das demais, além de reforçar suas posições. Benhabib argumenta, nesse sentido, que as denúncias feitas por Butler e Cornell de leituras incorretas de seus respectivos textos insinuam que "qualquer desacordo implica má interpretação ou compreensão falha" - hipótese que ela denomina de "autoindulgente", pois a incompreensão pode resultar de problemas como a falta de clareza dos textos (Seyla BENHABIB, 2018, p. 166). Por outro lado, Butler classifica o trabalho do volume como "entristecedor" (Judith BUTLER, 2018, p. 190), pois o apego das pensadoras (dela inclusive) às suas posições impediu, por vezes, a compreensão do que estava em jogo nos postulados das outras. Cornell defende a articulação entre teoria crítica e as vertentes genericamente chamadas pós-modernas em perspectivas feministas e recusa veementemente a ideia de "sujeito autoidêntico", incluindo o "sujeito autoidêntico do feminismo" (Drucilla CORNELL, 2018 , p. 230). Fechando o volume, Fraser tenta, novamente, estabelecer uma espécie de diálogo entre os posicionamentos distintos das outras três autoras. Para ela, os debates feministas apresentados relacionam-se, todos, com a assim chamada "virada linguística" que caracteriza muitas posições teóricas contemporâneas. Seria necessário absorver o que cada uma das contribuições tem de melhor em função do desenvolvimento de "uma teoria feminista eclética, neopragmática" (Nancy FRASER, 2018, p. 253). 
É possível perceber que os impasses mais pronunciados da segunda parte do livro desvelam uma crítica passível de ser feita ao resultado final. De fato, por vezes, a tentativa de defender as próprias posições teóricas se sobrepõe à tentativa de apresentar as possibilidades oferecidas pela crítica feminista para a luta contra a dominação masculina. Em algumas passagens, a ânsia em responder à crítica ou em desconstruir o argumento alheio é mais forte do que a de veicular a própria compreensão do pensamento feminista - esse aspecto perturba, em alguns momentos, a fluidez de leitura dos argumentos. De todo modo, quando as divergências são lidas como próprias de um tipo de reflexão que se inscreve contra tradições hegemônicas que se impuseram ao longo da história do pensamento ocidental como universais, elas são muito bem-vindas.

Outro ponto crítico é o fato de o livro não incorporar nenhuma representante do feminismo negro, embora, sintomaticamente, todas as quatro autoras mencionem a importância de situar as intersecções entre raça e gênero no debate feminista. De todo modo, a introdução deixa claro que o volume "não pretende fornecer nenhum tipo de panorama sobre a teoria feminista contemporânea", mesmo porque ele incorpora "quatro mulheres brancas dos Estados Unidos", provenientes de uma disciplina particular (Linda NICHOLSON, 2018, p. 10).

Por fim, é necessário um alerta para quem espera uma explanação clara e unívoca a respeito da concepção de feminismo. Tal público certamente irá se decepcionar e terá que enfrentar a aridez de debates filosóficos e teórico sociais complexos, díspares, confrontativos e plurais, nem sempre apreensíveis na primeira leitura. As interlocuções teóricas estabelecidas pelas pensadoras acabam exigindo uma formação teórica mínima prévia das leitoras e dos leitores, ainda que elas façam o esforço de apresentar sucintamente seus referenciais. De todo modo, nem sempre há sucesso em tal tentativa. O primeiro ensaio de Cornell, por exemplo, vale-se de muitas tradições teóricas distintas para construir seu argumento e o resultado é um diálogo nem sempre claramente exposto.

De qualquer forma, o livro, ainda que publicado tardiamente no Brasil, anuncia-se como leitura necessária às interessadas e aos interessados em teoria feminista. Mais do que isso: em suas muitas interlocuções teóricas, as feministas em questão acabam denunciando que, se no princípio o "verbo" filosófico permaneceu definitivamente sexualizado, a participação das mulheres é uma exigência de qualquer teoria que deseje romper com as falácias da objetividade teórica, da unidade do sujeito e da linearidade da história. Como formulou Jeanne Marie Gagnebin (2005, p. 48), "porque o sujeito não é somente um, mas múltiplo e variável, porque o tempo se espalha em redes temporais diversas, porque a história tem solavancos, acelera ou, de repente, desmorona", há uma abertura na teoria social e na filosofia contemporâneas para "outras línguas", das quais as mulheres aparecem em Debates feministas como uma das indispensáveis portadoras.

\section{Referências}

BENHABIB, Seyla. "Feminismo e pós-modernidade: uma aliança complicada". In: BENHABIB, Seyla; BUTLER, Judith; CORNELL, Drucilla; FRASER, Nancy. Debates feministas. Um intercâmbio filosófico. Trad. de Fernanda Veríssimo. São Paulo: Editora Unesp, 2018, p. 35-59.

BENHABIB, Seyla. "Subjetividade, historiografia e política: reflexões sobre o 'debate feminismo/pósmodernismo". In: BENHABIB, Seyla; BUTLER, Judith; CORNELL, Drucilla; FRASER, Nancy. Debates feministas. Um intercâmbio filosófico. Trad. de Fernanda Veríssimo. São Paulo: Editora Unesp, 2018, p. 163-187.

BENHABIB, Seyla; BUTLER, Judith; CORNELL, DRUCILLA; FRASER, Nancy. Debates feministas. Um intercâmbio filosófico. Trad. de Fernanda Veríssimo. São Paulo: Editora Unesp, 2018.

BENHABIB, Seyla; CORNELL, Drucilla (Orgs.). Feminismo como crítica da modernidade. Trad. de Nathanael da Costa Caixeiro. Rio de Janeiro: Rosa dos Tempos, 1987.

BUTLER, Judith. "Fundações contingentes: feminismo e a questão do 'pós-modernismo'”. In: BENHABIB, Seyla; BUTLER, Judith; CORNELL, Drucilla; FRASER, Nancy. Debates feministas. Um intercâmbio filosófico. Trad. de Fernanda Veríssimo. São Paulo: Editora Unesp, 2018, p. 61-92.

BUTLER, Judith. "Por uma leitura cuidadosa". In: BENHABIB, Seyla; BUTLER, Judith; CORNELL, Drucilla; FRASER, Nancy. Debates feministas. Um intercâmbio filosófico. Trad. de Fernanda Veríssimo. São Paulo: Editora Unesp, 2018, p. 189-213.

BUTLER, Judith. Problemas de gênero: feminismo e subversão da identidade. Trad. de Renato Aguiar. Rio de Janeiro: Civilização Brasileira, 2003.

CORNELL, Drucilla. "O que é feminismo ético?". In: BENHABIB, Seyla; BUTLER, Judith; CORNELL, Drucilla; FRASER, Nancy. Debates feministas. Um intercâmbio filosófico. Trad. de Fernanda Veríssimo. São Paulo: Editora Unesp, 2018, p. 117-160. 
CORNELL, Drucilla. "Repensando o tempo do feminismo". In: BENHABIB, Seyla; BUTLER, Judith; CORNELL, Drucilla; FRASER, Nancy. Debates feministas. Um intercâmbio filosófico. Trad. de Fernanda Veríssimo. São Paulo: Editora Unesp, 2018, p. 215-231.

FRASER, Nancy. "Falsas antíteses: uma resposta a Seyla Benhabib e Judith Butler". In: BENHABIB, Seyla; BUTLER, Judith; CORNELL, Drucilla; FRASER, Nancy. Debates feministas. Um intercâmbio filosófico. Trad. de Fernanda Veríssimo. São Paulo: Editora Unesp, 2018, p. 93-115.

FRASER, Nancy. "Pragmatismo, feminismo e a virada linguística". In: BENHABIB, Seyla; BUTLER, Judith; CORNELL, Drucilla; FRASER, Nancy. Debates feministas. Um intercâmbio filosófico. Trad. de Fernanda Veríssimo. São Paulo: Editora Unesp, 2018, p. 233-253.

GAGNEBIN, Jeanne Marie. "As flautistas, as parteiras e as guerreiras". In: GAGNEBIN, Jeanne Marie. Sete aulas sobre linguagem, memória e história. Rio de Janeiro: Imago, 2005, p. 37-46.

NICHOLSON, Linda. "Introdução". In: BENHABIB, Seyla; BUTLER, Judith; CORNELL, Drucilla; FRASER, Nancy. Debates feministas. Um intercâmbio filosófico. Trad. de Fernanda Veríssimo. São Paulo: Editora Unesp, 2018, p. 9-31.

Patrícia da Silva Santos (patricia215@gmail.com) é professora da Faculdade de Ciências Sociais e do Programa de Pós-Graduação em Sociologia e Antropologia da Universidade Federal do Pará. É doutora em Sociologia pela Universidade de São Paulo, tendo realizado período de doutorado sanduíche na Universidade de Munique (Alemanha). Realizou pesquisa de pósdoutorado no Deutsches Literatur-Archiv Marbach (Alemanha) com bolsa do Hilde-Domin Fonds e, posteriormente, com bolsa da FAPESP, na Universidade Estadual de Campinas, onde atuou também como professora colaboradora. É autora dos livros Racionalidade moderna e Franz Kafka (IFCH/ Unicamp, 2007) e Sociologia e superfície (Unifesp, 2016), além de ter publicado diferentes artigos sobre teoria social, sociologia da cultura e desigualdade de gênero.

\section{COMO CITAR ESSE ARTIGO DE ACORDO COM AS NORMAS DA REVISTA}

SANTOS, Patrícia da Silva. "Feminismo, filosofia e teoria social: mulheres em debate". Revista Estudos Feministas, Florianópolis, v. 27, n. 3, e61405, 2019.

\section{CONTRIBUIÇÃO DE AUTORIA}

Não se aplica.

\section{FINANCIAMENTO}

Não se aplica.

\section{CONSENTIMENTO DE USO DE IMAGEM}

Não se aplica.

APROVAÇÃO DE COMITÊ DE ÉTICA EM PESQUISA

Não se aplica.

\section{CONFLITO DE INTERESSES}

Não se aplica.

\section{LICENÇA DE USO}

Este artigo está licenciado sob a Licença Creative Commons CC-BY International. Com essa licença você pode compartilhar, adaptar, criar para qualquer fim, desde que atribua a autoria da obra.

\section{HISTÓRICO}

